Care: Jurnal Ilmiah Ilmu Kesehatan Vol .7, No.1,2019,hal 37-44

Tersedia online di https://jurnal.unitri.ac.id/index.php/care

ISSN 2527-8487 (online)

ISSN 2089-4503 (cetak)

\title{
Pelaksanaan Kelas Ibu Hamil Sebagai Upaya Peningkatan Pengetahuan Ibu, Keluarga Dan Kader Dalam Deteksi Dini Resiko Tinggi Ibu Hamil Di Wilayah Kerja Puskesmas Sambeng Kabupaten Lamongan
}

\author{
Abdul Muhith ${ }^{1}$, Arief Fardiansyah ${ }^{2}$, Asih Media $Y^{3}$, Yenny Larasati ${ }^{4}$ \\ ${ }^{1}$ Associate Professor in Nursing Department of STIKes Majapahit; \\ ${ }^{2}$ Lecturer in Public Health Department of STIKes Majapahit Mojokerto \\ ${ }^{3}$ Lecturer Public Health Department of STIKes Majapahit Mojokerto \\ ${ }^{4}$ Public Health Dinas Kesehatan Lamongan \\ e-mail: abdulmuhith1979@gmail.com
}

\begin{abstract}
The introduction of high risk pregnant women is done through early detection of risk factors pro actively in all pregnant women by mother, family, and cadres. The program organized by the Ministry of Health to support the step is the Pregnant Women's Class. The purpose of this study is to improve knowledge of mother, family and cadres in early detection of high risk pregnant women in the working area of Sambeng Community Health Center of Lamongan. The design of this research is Quasi Experiment with Pre-Post Design approach. Its population is pregnant mother, family and cadres who attend class of pregnant mother in working area of UPT Sambeng Public Health Center. Sampling technique used was Purposive sampling, got 40 respondents of pregnant women, 40 families and 20 cadres. Data were analyzed with Wilcoxon Signed Ranks Test. Wilcoxon Signed Ranks Test results show that there is influence of maternal class implementation with knowledge of mother $(Z$ value $=-4,815)$, family $(Z$ value $=4,315)$ and cadre $(Z$ value $=-3,162)$ in early detection of high risk pregnant women. The success of pregnant women's classes can be continued by using innovative and attractive media such as simulation and movie viewing to be more engaging for the community, and families to participate, thus encouraging people to do early detection.
\end{abstract}

Keywords: cadras; family; knowledge; pregnant mother class

\begin{abstract}
ABSTRAK
Pengenalan ibu hamil yang beresiko tinggi dengan deteksi dini faktor resiko pada semua ibu hamil secara pro aktif oleh ibu, keluarga, dan kader. Kelas Ibu Hamil sebagai program Kementerian Kesehatan. Tujuan penelitian ini adalah untuk meningkatkan pengetahuan ibu, keluarga dan kader untuk deteksi dini ibu hamil beresiko tinggi di wilayah kerja puskesmas Sambeng Kabupaten Lamongan. Desain Quasi Experiment menggunakan pendekatan Pre-Post Design. Populasinya adalah ibu hamil, keluarga dan kader peserta 'kelas ibu hamil'. Tekhnik sampling menggunakan Purposive sampling, didapatkan responden sebanyak 40 ibu hamil, 40 keluarga dan 20 kader. Data dianalisis dengan Wilcoxon Signed Ranks Test. Hasil uji Wilcoxon Signed Ranks Test menunjukan bahwa ada pengaruh pelaksanaan 'kelas ibu hamil' dengan

Cara mengutip: Muhith,A., Fardiansyah A.,Media YA., Larasati Y.(2019). Pelaksanaan Kelas Ibu Hamil Sebagai Upaya Peningkatan Pengetahuan Ibu, Keluarga Dan Kader Dalam Deteksi Dini Resiko Tinggi Ibu Hamil Di Wilayah Kerja Puskesmas Sambeng Kabupaten Lamongan. Care:Jurnal Ilmiah Ilmu Kesehatan, 7(1), 37-44. Retrieved from https://jurnal.unitri.ac.id/index.php/care/article/view/1084
\end{abstract}


pengetahuan ibu $\left(Z_{\text {hitung }}=-4,845\right)$, keluarga $\left(Z_{\text {hitung }}=-4,315\right)$ dan kader $\left(Z_{\text {hitung }}=-3,162\right)$ dalam melakukan pendeteksian secara dini resiko tinggi ibu hamil. Keberhasilan kelas ibu hamil bisa dilanjutkan dengan menggunakan media yang inovatif dan atraktif seperti simulasi dan penayangan film agar lebih memikat masyarakat, dan keluarga untuk berpartisipasi sehingga mendorong masyarakat untuk melakukan deteksi dini.

Kata kunci : ibu; keluarga; kader, kelas ibu hamil; pengetahuan

\section{PENDAHULUAN}

Mengenalkan resiko tinggi pada ibu hamil dapat dilakukan dengan skrining/deteksi dini berbagai faktor resiko secara pro aktif terhadap semua ibu hamil, sebaiknya diawal kehamilan oleh para petugas kesehatan maupun non kesehatan namun terlatih di tengah masyarakat, misalnya ibu hamil, ibu PKK, karang taruna, keluarga, dan ibu kader. Adanya harapn agar kesadaran ibu hamil meningkat dengan adanya program 'kelas ibu hamil' yang diselenggarakan oleh Kementrian Kesehatan. Semua upaya ini tidak lepas dari keinginan pemerintah untuk menurunkan angka kematian ibu (Puspitasari, 2012).

Indikator kritis dalam status kesehatan ibu adalah Angka Kematian Ibu (AKI). Kematian ibu menjadi beban berat bagi kehidupan keluarga, terlebih lagi akan memberikan pengaruh kesehatan yang buruk serta usia kehidupan anggota dari keluarga yang ditinggalkan. World Health Organization (WHO) tahun 2017 memperkirakan sekitar $75-85 \%$ dari seluruh wanita hamil akan berkembang menjadi komplikasi yang berkaitan dengan kehamilannya serta mengancam jiwanya. Departemen Kesehatan mengungkapkan tahun 2015 AKI di Indonesia sekitar 359/100.000 kelahiran hidup, dengan penyebab utama sebesar $90 \%$ saat persalinan dan segera setelah persalinan. Penyebab langsung kematian ibu yaitu di Jawa Timur mencapai 89,6 per 100.000 kelahiran hidup. Angka kematian ibu tertinggi di Kabupaten Bondowoso sebanyak 19 orang dan terendah di Kabupaten Madiun sebanyak 4 orang. Walalupun capaian AKI di Jawa Timur sudah memenuhi target Renstra dan MDG's AKI harus tetap ditekan.

Dinas Kesehatan Kabupaten Lamongan menyampaikan AKI di Lamongan tahun 2017 yaitu sebesar 54/100.000 kelahiran hidup. Sedangkan jumlah kematian maternal oleh petugas kesehatan sebesar 10 orang terdiri dari kematian ibu hamil sebanyak 1 orang, ibu bersalin sebanyak 7 orang dan ibu nifas sebanyak 2 orang, dengan penyebab kematian sebagian besar karena perdarahan pada saat persalinan. 
Dari hasil studi pendahuluan telah dilaksanakan 'Kelas Ibu Hamil' di Kecamatan Sambeng Kabupaten Lamongan pada tanggal 22 Desember 2017 dengan menggunakan quisioner kepada 10 orang responden, sebagian besar mereka kurang mengetahui tentang resiko tinggi ibu hamil sebanyak 8 orang $(80 \%)$, dan hanya 2 orang yang memahami tentang resiko tinggi ibu hamil.

\section{METODE PENELITIAN}

Desain menggunakan Quasi Experiment, pendekatan Pre-Post Design. Populasinya adalah ibu hamil, keluarga dan kader yang mengikuti kelas ibu hamil di wilayah kerja UPT Puskesmas Sambeng. Tekhnik sampling menggunakan Purposive sampling, didapatkan responden sebanyak $40 \mathrm{ibu}$ hamil, 40 keluarga dan 20 kader. Instrumen berupa kuesioner ibu hamil yang mengacu pada buku Pedoman Pelaksanaan Kelas Ibu Hamil (Depkes RI, 2009). 'Wilcoxon Signed Ranks Test' adalah uji statistik yang digunakan untuk mengetahui pengaruh kelas ibu hamil dikaitkan pengetahuan ibu, keluarga dan kader dalam deteksi dini resiko ibu hamil.

\section{HASIL}

Hasil penelitian dari segi usia diketahui sebagian besar ibu hamil yakni 33 ibu $(82,5 \%)$ berusia $20-35$ tahun, sebanyak
$4 \mathrm{ibu}(10 \%)$ berusia $>35$ tahun, dan sebanyak 3 ibu (7,5\%) berusia kurang dari 20 tahun.

Tabel 1 Distribusi Frekuensi Keluarga

\begin{tabular}{lcc}
\hline $\begin{array}{l}\text { Karakteristik } \\
\text { Keluarga }\end{array}$ & Jumlah & $\%$ \\
\hline Usia (Tahun) & & \\
\hline a. $<20$ & 3 & 7,5 \\
b. $20-35$ & 25 & 62,5 \\
c. $>35$ & 12 & 30 \\
\hline
\end{tabular}

\section{Status Keluarga}

Ibu

\begin{tabular}{lcc}
\hline a. Suami & 3 & 7,5 \\
b. Saudara & 31 & 77,5 \\
c. Orang Tua & 6 & 15 \\
\hline Jenis Kelamin & & \\
\hline a. Laki-Laki & 3 & 7,5 \\
b. Perempuan & 37 & 92,5 \\
\hline Pekerjaan & & \\
\hline a. Petani & 28 & 70 \\
b. Swasta & 3 & 7,5 \\
c. Wiraswasta & 4 & 10 \\
d. Dagang & 5 & 12,5 \\
\hline Pendidikan & & \\
\hline a. SLTP/ Sederajat & 12 & 30 \\
b. SLTA/ Sederajat & 26 & 65 \\
c. Perguruan Tinggi & 2 & 5 \\
\hline
\end{tabular}

Tabel 2 Distribusi Frekuensi

\begin{tabular}{lcc}
\hline $\begin{array}{l}\text { Karakteristik } \\
\text { Kader }\end{array}$ & Jumlah & $\%$ \\
\hline Usia (Tahun) & & \\
\hline a. 20 - 35 & 11 & 55 \\
b. $>35$ & 9 & 45 \\
\hline Pekerjaan & & \\
\hline a. Petani & 14 & 70 \\
b. Wiraswasta & 5 & 25 \\
c. Dagang & 1 & 5 \\
\hline Pendidikan & & \\
\hline a. SLTP/ Sederajat & 8 & 40 \\
b. SLTA/ Sederajat & 12 & 60 \\
\hline
\end{tabular}


Karakteristik responden berdasarkan usia kehamilan(trimester) diketahui sebanyak

$17 \mathrm{ibu}(42,5 \%)$ berada di trimester III, sebanyak $16 \mathrm{ibu}(40 \%)$ trimester II, dan $7 \mathrm{ibu}(17,5 \%)$ trimester I.

Tabel 3 Analisis Pengetahuan Ibu Hamil Sebelum dan Sesudah Kelas Ibu Hamil

\begin{tabular}{|c|c|c|c|c|}
\hline \multirow{2}{*}{$\begin{array}{c}\text { Pengetahuan } \\
\text { Bumil }\end{array}$} & \multicolumn{2}{|c|}{ Sebelum (Pre) } & \multicolumn{2}{|c|}{ Setelah (Post) } \\
\hline & Jumlah & $\%$ & Jumlah & $\%$ \\
\hline Kurang & 13 & 32,5 & 1 & 2,5 \\
\hline Cukup & 20 & 50 & 13 & 32,5 \\
\hline Baik & 7 & 17,5 & 26 & 65 \\
\hline \multicolumn{5}{|c|}{$Z_{\text {hitung }}=-4,670$ p value $=0,000$} \\
\hline
\end{tabular}

Tabel 4 Analisis Pengetahuan Keluarga Sebelum dan Sesudah Kelas Ibu Hamil

\begin{tabular}{lcccc}
\hline \multicolumn{1}{c}{ Pengetahuan } & \multicolumn{2}{c}{ Sebelum (Pre) } & \multicolumn{2}{c}{ Setelah (Post) } \\
\cline { 2 - 5 } & Jumlah & $\%$ & Jumlah & $\%$ \\
\hline Kurang & 14 & 35 & 1 & 2,5 \\
Cukup & 18 & 45 & 13 & 32,5 \\
Baik & 8 & 20 & 26 & 65 \\
\hline \multicolumn{2}{c}{$n=40}$, & $Z_{\text {bitung }}=-4,160$ & p value $=0,000$ \\
\hline
\end{tabular}

Tabel 5 Analisis Pengetahuan Kader Sebelum dan Sesudah Kelas Ibu Hamil

\begin{tabular}{lcccc}
\hline \multicolumn{1}{c}{ Pengetahuan } & \multicolumn{2}{c}{ Sebelum (Pre) } & \multicolumn{3}{c}{ Setelah (Post) } \\
\cline { 2 - 5 } & Jumlah & $\%$ & Jumlah & $\%$ \\
\hline Kurang & 8 & 40 & 0 & 0 \\
Cukup & 7 & 35 & 4 & 20 \\
Baik & 5 & 25 & 16 & 80 \\
\hline & $n=20$, & $Z_{\text {hitung }}=-3,416$ & p value $=0,001$ & \\
\hline
\end{tabular}

Karakteristik responden berdasarkan riwayat kehamilan, diketahui sebanyak 37 ibu(92,5\%) mengalami kehamilan 1-3 kali, dan 3 ibu (7,5\%) ibu lebih dari 3 kali kehamilan. Sebanyak 100\% ibu sebagai ibu rumah tangga.

Karakteristik ibu berdasarkan pendidikan, sebanyak $30 \mathrm{ibu}(75 \%)$ berpendidikan
SLTA/sederajat dan 10 ibu (25\%) berpendidikan SLTP/sederajat.

\section{PEMBAHASAN}

Pengaruh Pelaksanaan 'Kelas Ibu Hamil' Terhadap Pengetahuan Ibu Hamil

Tabel 3 memperlihatkan bahwa sebelum dilaksanakan kelas bumil pengetahuan ibu hamil tentang deteksi dini resiko ibu hamil yang kurang sebanyak 32,5\% namun setelah kelas ibu hamil dilaksanakan 
subyek penelitian yang tergolong berpengetahuan kurang menurun menjadi 2,5\% (1 orang). Hasil uji statistik menunjukkan $\mathrm{p}$ value sebesar 0,000 dengan nilai $Z$ Hitung -4,670 yang berarti ada pengaruh pelaksanaan kelas ibu hamil terhadap peningkatan pengetahuan ibu hamil dalam medeteksi dini resiko tinggi ibu hamil.

Menurut Notoadmodjo (2012) banyak hal yang menentukan pengetahun yakni pendidikan, mass media/informasi, sosial budaya dan ekonomi, lingkungan, pengalaman dan usia. peningkatan pengetahuan seseorang bisa karena kematangan usia dan pendidikannya. Sebagian besar usia ibu hamil 20-30 tahun serta berpendidikan SLTA. Dengan kematangan usia dan pendidikan yang mencapai pendidikan dasar menjadikan seseorang berfiir lebih matang dan dewasa serta mudah menerima informasi dan menetukan mana yang baik bagi dirinya dan keluarga. Satu orang subyek penelitian yang memiliki pengetahuan kurang meskipun sudah dilakukan kelas ibu hamil dikarenakan ibu tersebut buru-buru mengisi kuesioner karena anaknya tdak ada yang menjaga.

Depkes RI (2009) menyatakan bahwa sosial budaya yang dianut oleh masyarakat setempat juga mempengaruhi terbentuknya perilaku sesorang. Pengetahuan ibu kurang lebih terkait pada penyakit seksual menular (HIV-AIDS) dan kebiasaan seksual saat hamil. Beberapa ibu saat kelas ibu banyak yang menanyakan bagaimana aktifitas seksual yang aman untuk ibu hamil. 10 orang ibu hamil juga menyatakan bahwa mereka tidak pernah tahu jika boleh merencanakan untuk melahirkan dimana dan mempersiapkan segala kebutuhan calon bayi yang akan dilahirkan karena takut "pamali" atau "kualat". Faktor sosial budaya di Indonesia yang berbeda-beda disetiap daerah merupakan bagian eksternal terbentuknya perilaku kesehatan seseorang.

Hasil penelitian ini sejalan dengan penelitian Putri (2014) yang menyatakan bahwa ada keterkaitan antara kelas ibu hamil dengan pengetahuan ibu tentang tanda bahaya kehamilan dan Tinah (2015) tentang pelaksanaan kelas ibu hamil dengan pengetahuan ibu dalam deteksi resiko tinggi ibu hamil.

\section{Pengaruh Pelaksanaan Kelas Ibu Hamil Terhadap Pengetahuan Keluarga}

Pada Tabel 4 terlihat bahwa pengetahuan keluarga ibu hamil tentang deteksi dini resiko ibu hamil sebelum dilaksanakan 
kelas ibu hamil didapati 35\% subyek penelitian memiliki pengetahuan kurang dan setelah pelaksanaan kelas ibu menurun menjadi 2,5\%. Kader yang memiliki kemampuan baik sebelum dilakukan intervensi sebanyak $20 \%$ dan meningkat menjadi 65\% setelah dilakukan intervensi.

Sarafino dan Smith (2014) menyatakan dukungan sosial merupakan kesenangan yang dirasakan sebagai perhatian, penghargaan atau pertolongan yang diterima dari orang lain atau suatu kelompok salah satunya adalah dukungan dari keluarga.

Pada penelitian ini sosial budaya keluarga masih dipengaruhi adat dan kebiasaan masyarakat setempat. Pertanyaan dalam kuesioner yang sulit dipahami oleh keluarga adalah pertanyaan nomor 4 tentang pendapat pentingnya merencanakan pesalinan, karena di wilayah Sambeng ada budaya bahwa melahirkan tidak boleh direncanakan biarkan berjalan apa adanya.

Tingginya angka kematian ibu dan bayi di Indonesia sebagian besar disebabkan oleh timbulnya penyulit persalinan yang tidak segera di rujuk ke fasilitas kesehatan yang lebih baik. Penanganan dan rujukan ibu beresiko sejak dini serta identifikasi tempat persalinan yang tepat bagi ibu hamil sesuai dengan resiko kehamilan yang disandang (Dinkes Lamongan, 2015). Pentingnya kelas ibu hamil bagi keluarga diharapakan dapat meningkatkan pengetahuan keluarga dalam meningkatkan deteksi dini resiko tinggi ibu hamil. Faktor resiko ibu hamil memungkinkan terjadinya komplikasi persalinan dengan resiko kematian pada ibu dan bayi

\section{Pengaruh Pelaksanaan Kelas Ibu Hamil Terhadap Pengetahuan Kader tentang Deteksi Dini Resiko Ibu Hamil}

Tabel 5 menunjukkan bahwa pengetahuan kader sebelum dilaksanakan kelas ibu hamil 40\% memiliki pengetahuan kurang, $35 \%$ cukup. Setelah dilakukan kelas ibu hamil pengetahuan kader meningkat. Tidak ada kader yang berpengetahuan rendah dan yang berpengetahuan baik meningkat menjadi 80\% setelah mengikuti kelas ibu hamil. Hasil Uji statistik wilcoxon didapatkan hasil $\mathrm{p}$ value sebesar 0,001 dengan Z-hitung sebesar -3,416 yang berarti ada pengaruh kelas ibu hamil terhadap pengetahuan kader dalam deteksi dini resiko ibu hamil.

Hani (2010) menyatakan bahwa metode tatap muka dalam 'kelas ibu hamil' bertujuan meningkatkan ketrampilan dan 
pengetahuan ibu-ibu tentang kehamilan dan persalinan, , perawatan saat nifas dan perawatan untuk bayi baru lahir, melalui praktik dengan acuan buku panduan. Kelas ibu pada penelitian ini dilakukan mengacu pada buku pedoman pelaksanaan kelas ibu dari departemen kesehatan yang berisi tentang deteksi dini resiko ibu hamil mulai dari masa kehamilan sampai pada masa nifas.

Notoadmodjo (2010) menyatakan faktor yang dapat mempengaruhi perilaku kesehatan yakni faktor penguat yaitu faktor yang dapat memberikan pengaruh kuat untuk keberlanjutan dan kontribusinya terhadap penyebaran materi. Dari 20 kader yang menjadi responden 10 diantaranya telah menjadi kader selama lebih dari 5 tahun sehingga mereka sudah sering juga terpapar oleh informasi dari petugas kesehatan berpengetahuan baik. Kader berpengetahuan cukup setelah pelaksanaan 'kelas ibu hamil' diantaranya karena tempat tinggal mereka jauh dari fasilitas kesehatan dan mereka juga jarang hadir di kegiatan kesehatan. Untuk mengatasi kendala tersebut petugas kesehatan beberapa kali melakukan pendekatan pada kader agar mereka aktif untuk hadir di kegiatan bertema kesehatan seperti kelas ibu hamil.
Faktor penguat untuk mengubah perilaku masyarakat salah satunya adalah peran serta kader. Peran serta kader dalam menyampaikan informasi kesehatan kepada masyarakat mesti dioptimalkan meskipun ada beberapa kendala yang ditemui saat bersama dengan masyarakat. Peran kader pada penelitian ini lebih di tekankan pada tanda-tanda dan gejala kelainan pada kehamilan serta dukungannya dalam menginformasikan kepada ibu hamil dan keluarga pentingnya merencanakan tempat melahirkan sesuai dengan pertanyaan yang ada pada kuesioner kader. Kader masih percaya dengan budaya setempat yang tabu untuk merencanakan tempat melahirkan.

\section{KESIMPULAN}

Dari hasil analisa data dapat disimpulkan bahwa ada pelaksanaan 'kelas ibu hamil' berpengaruh terhadap peningkatan pengetahuan ibu hamil, keluarga dan kader kesehatan dalam deteksi dini resiko ibu hamil.

Diharapkan ibu hamil, keluarga dan kader memiliki peran aktif dalam mendeteksi resiko ibu hamil, dan bekerjasama dengan petugas kesehatan demi menciptakan desa dan keluarga siaga. 


\section{REFERENSI}

Depkes, RI.(2009). Sistem Kesehatan Nasional. Jakarta

Hani Umi, dkk.(2010). Asuban kebidanan Pada Kehamilan Fisiologi. Penerbit:Salemna Medika. EGC. Jakarta

Notoatmodjo, S. (2012) Metodologi Penelitian Kesehatan, Jakarta: Rineka Cipta.

Puspitasari Indah, Dwi. (2017). Teknik Massage Punggung Untuk Mengurangi Persalinan Kala I. Jurnal Ilmu Keperawatan dan Kebidanan Vol.8. No.2, p100-106

Putri, K \& Denny Y. (2014). Analisis Faktor yang Berhubungan dengan Kepatuhan Menggunakan Alat Pelindung Diri. The Indonesian Journal of Occupational Safety, Health and Environment, Vol. 1, No. 1 Jan-April 2014: 24-36.

Sarafino, E. P., \& Smith, T. W. (2014). Health Psychology Eight Edition. USA: John Wiley \& Sons, Inc 